\title{
Comparing simulated atmospheric carbon dioxide concentration with GOSAT retrievals
}

\author{
Huifang Zhang $\cdot$ Baozhang Chen $\cdot$ Guang Xu $\cdot$ \\ Jianwu Yan $\cdot$ Mingliang Che $\cdot$ Jing Chen $\cdot$ \\ Shifeng Fang $\cdot$ Xiaofeng Lin $\cdot$ Shaobo Sun
}

Received: 10 May 2014/Accepted: 31 August 2014/Published online: 7 January 2015

(C) Science China Press and Springer-Verlag Berlin Heidelberg 2015

\begin{abstract}
Satellite observations of atmospheric carbon dioxide $\left(\mathrm{CO}_{2}\right)$ provide a useful way to improve the understanding of global carbon cycling. In this paper, we present a comparison between simulated $\mathrm{CO}_{2}$ concentrations from an inversion model of the CarbonTracker Data Assimilation System (CTDAS) and satellite-based $\mathrm{CO}_{2}$ measurements of column-averaged dry air mole fraction (denoted $\mathrm{XCO}_{2}$ ) derived from version 3.3 Atmospheric $\mathrm{CO}_{2}$ Observations from Space retrievals of the Greenhouse Gases Observing SATellite (ACOS-GOSAT) L2 data products. We examine the differences of CTDAS and GOSAT to provide important guidance for the further investigation of CTDAS in order to quantify the corresponding flux estimates with satellite-based $\mathrm{CO}_{2}$ observations. We find that the mean point-by-point difference (CTDAS-GOSAT) between CTDAS and GOSAT $\mathrm{XCO}_{2}$ is $-0.11 \pm 1.81 \mathrm{ppm}$, with a high agreement (correlation $r=0.77, P<0.05$ ) over the studied period. The latitudinal zonal variations of CTDAS and GOSAT are in general agreement with clear seasonal fluctuations. The major
\end{abstract}

H. Zhang · B. Chen $(\varangle) \cdot$ G. Xu · M. Che $\cdot$ J. Chen $\cdot$ S. Fang

X. Lin. S. Sun

State Key Laboratory of Resources and Environment Information System, Institute of Geographic Sciences and

Natural Resources Research, Chinese Academy of Sciences,

Beijing 100101, China

e-mail: baozhang.chen@igsnrr.ac.cn

H. Zhang $\cdot$ G. Xu $\cdot$ M. Che $\cdot$ X. Lin $\cdot$ S. Sun

University of Chinese Academy of Sciences, Beijing 100049, China

J. Yan

Department of Tourism and Environmental Sciences, Shaanxi Normal University, Xi'an 710062, China exception occurs in the zonal band of $0^{\circ}-15^{\circ} \mathrm{N}$ where the difference is approximately $4 \mathrm{ppm}$, indicating that large uncertainty may exist in the assimilated $\mathrm{CO}_{2}$ for the lowlatitude region of the Northern Hemisphere $(\mathrm{NH})$. Additionally, we find that the hemispherical/continental differences between CTDAS and GOSAT are typically less than $1 \mathrm{ppm}$, but obvious discrepancies occur in different hemispheres/continents, with high consistency (point-bypoint correlation $r=0.79, P<0.05$ ) in the $\mathrm{NH}$ and a weak correlation (point-by-point correlation $r=0.65, P<0.05$ ) in the Southern Hemisphere. Overall, the difference of CTDAS and GOSAT is small, and the comparison of CTDAS and GOSAT will further instruct the inverse modeling of $\mathrm{CO}_{2}$ fluxes using GOSAT.

Keywords CTDAS model $\cdot$ Satellite-based $\mathrm{CO}_{2}$ concentration · GOSAT · Comparison · Inversion method

\section{Introduction}

Accurate quantification of biosphere fluxes of $\mathrm{CO}_{2}$ is critical to understanding global and regional carbon cycles $[1,2]$. The atmospheric inversion method provides an effective way to quantify the biosphere $\mathrm{CO}_{2}$ concentration/ flux at the full-coverage spatial resolutions [3-7]. This approach derives the $\mathrm{CO}_{2}$ concentrations and fluxes jointly from an atmospheric transport model and data assimilation technique. Unlike ecosystem modeling [8-15], the inverted method uses the atmospheric $\mathrm{CO}_{2}$ transport process mechanism to describe the $\mathrm{CO}_{2}$ spatiotemporal variations and uses the time-dependent Bayesian synthesis method to optimize the $\mathrm{CO}_{2}$ concentrations and fluxes. This is advantageous for $\mathrm{CO}_{2}$ estimation because the 
concentrations and fluxes can be constrained well by the observations in the inversion model. However, because of the sparseness of the existing $\mathrm{CO}_{2}$ mixing ratio observation sites, the inversion estimate of $\mathrm{CO}_{2}$ concentrations and $\mathrm{CO}_{2}$ source and sink information remain unclear [16-19].

Satellite-based $\mathrm{CO}_{2}$ observations of column-averaged dry air mole fraction $\left(\mathrm{XCO}_{2}\right)$ offer a new insight into the pattern of $\mathrm{CO}_{2}$ mixing ratios and provide an additional constraint on the estimated $\mathrm{CO}_{2}$ concentrations and fluxes of the atmospheric inversion method [16, 19-22]. These satellite-based measurements (e.g., GOSAT [23], AIRS [24], SCIAMACHY [25] and IASI [26]) allow for the quantification of large-scale temporal, spatial and seasonal variations in $\mathrm{CO}_{2}$. As the first-dedicated greenhouse gas sensor [19, 23], GOSAT has been particularly useful for improving estimates of $\mathrm{CO}_{2}$ concentrations and decreased uncertainties of $\mathrm{CO}_{2}$ sources and sinks by providing further constrains on the inversion method [26-28], since it was specifically designed for monitoring high-precision observations of $\mathrm{CO}_{2}$ concentrations with sensitivity in the lower troposphere [23, 29]. However, errors in GOSAT observations and models still need to be identified and minimized before these satellite-based measurements are assimilated into the inversion model, as they could lead to additional uncertainties of the inferred $\mathrm{CO}_{2}$ concentrations and fluxes and result in misinterpretation of the global and regional carbon cycles. In this context, we present a comparison between GOSAT $\mathrm{XCO}_{2}$ retrieved from version 3.3 Atmospheric $\mathrm{CO}_{2}$ Observations from Space retrievals of the Greenhouse Gases Observing SATellite (ACOS-GOSAT) L2 data products [30-32] with the CarbonTracker Data Assimilation System (CTDAS) $[6,33] \mathrm{CO}_{2}$ concentrations during April 2009-December 2010. We examined the differences of CTDAS and GOSAT to provide important guidance for the further investigation of CTDAS in order to quantify the corresponding flux estimates with satellite-based $\mathrm{CO}_{2}$ observations.

\section{Methods and data}

\subsection{GOSAT $\mathrm{XCO}_{2}$ retrievals}

We use the GOSAT $\mathrm{XCO}_{2} \mathrm{~L} 2$ data products (Version 3.3) from the NASA Atmospheric $\mathrm{CO}_{2}$ Observations from Space (ACOS3.3) $\mathrm{XCO}_{2}$ retrievals [30-32] to compare with our CTDAS $\mathrm{XCO}_{2}$ retrievals during April 2009December 2010. These ACOS3.3 $\mathrm{XCO}_{2}$ retrievals have already been evaluated by comparison with ground-based measurements of $\mathrm{XCO}_{2}$ from Total Column Observing Network (TCCON) stations [30, 31] and have been successfully employed in many previous works [32, 34-36]. The ACOS3.3 $\mathrm{XCO}_{2}$ retrievals were downloaded from
NASA Goddard Earth Sciences Data (http://disc.sci.gsfc. nasa.gov/acdisc/documentation/ACOS.shtml) for this study. Compared to the $\mathrm{ACOS} 2.9, \mathrm{ACOS} 3.3 \mathrm{XCO}_{2}$ retrievals have changed their $\mathrm{CO}_{2}$ absorption cross sections to 2.06 micro-bands, which are systematically $\sim 1 \%$ lower than the $\mathrm{XCO}_{2}$ retrievals using 1.61 micro-bands, resulting in large differences in measurement values. Note that before the ACOS3.3 $\mathrm{XCO}_{2}$ were used in this study, we applied an updated screening criteria to filter out the $\mathrm{ACOS} 3.3 \mathrm{XCO}_{2}$ measurements and corrected their biases according to the reference of "ACOS Level 2 Standard Product Data User's Guide, version 3.3" (available from http://disc.sci.gsfc.nasa.gov/datareleases/acos-version-3.3).

\subsection{CTDAS model}

CTDAS (http://carbontracker.eu/ctdas/) [6, 33] was developed to estimate the global $\mathrm{CO}_{2}$ surface fluxes and atmospheric $\mathrm{CO}_{2}$ concentration distribution with high accuracy and precision [4, 6, 37-41]. First, the system forecasted the atmospheric $\mathrm{CO}_{2}$ concentrations using the transport model TM5 [42] and then optimized these modeled $\mathrm{CO}_{2}$ concentrations and flux fields using the data assimilation technique in CTDAS. In this study, we ran CTDAS using weekly resolution and a 5-week lag window to retrieve the volume mixing ratio of $\mathrm{CO}_{2}\left(\mathrm{CTDAS} \mathrm{XCO}_{2}\right)$ sampled at GOSAT locations and times, based on method of Rodgers and Connor [43]. The CTDAS simulation spanned the period from 2008 to 2010, but the period from January 2008 to March 2009 was used as a spin-up period to initialize the model and was therefore excluded from our analysis. The driving meteorological data in CTDAS were from the European Centre for Medium-Range Weather Forecasts (ECMWF, http://www.ecmwf.int/research/ ifsdocs/CY28r1/index.html), and CTDAS was forced by four prior surface fluxes: (1) the first guess biosphere flux extracted from the Carnegie-Ames-Stanford Approach (CASA, http://geo.arc.nasa.gov/sge/casa/index4.html) [44]; (2) the fossil fuel emissions integrated from the Carbon Dioxide Information and Analysis Center (CDIAC) [45] and the Emission Database for Global Atmospheric Research (EDGAR) database [46]; (3) the biomass burning emissions obtained from Global Fire Emission Database version 2 (GFED2, http://ess1.ess.uci.edu/jranders/data/ GFED2); and (4) the prior ocean fluxes derived from airsea partial pressure difference [47]. The $\mathrm{CO}_{2}$ measurements at the surface were assimilated in this system from the National Oceanic and Atmospheric Administration's Earth System Research Laboratory (NOAA-ESRL, http:// www.esrl.noaa.gov/gmd/ccgg/obspack/). The simulated 4-D $(x, y, z, t) \mathrm{CO}_{2}$ concentration fields contain 25 vertical layers with a global horizontal resolution of $6^{\circ} \times 4^{\circ}$. 


\section{Results and discussion}

\subsection{Comparison between CTDAS and GOSAT}

Here, we compare the estimated CTDAS $\mathrm{XCO}_{2}$ with the observed GOSAT $\mathrm{XCO}_{2}$ retrievals. Our CTDAS $\mathrm{XCO}_{2}$ was calculated based on the GOSAT averaging kernel and prior profile. Following the method of Rodgers et al. [43], the retrieved $\mathrm{XCO}_{2}$ of CTDAS can be expressed as:

$\mathrm{XCO}_{2}=\mathrm{h}^{\mathrm{T}} X_{a}+\mathrm{h}^{\mathrm{T}} \mathbf{A}\left(X_{h}-X_{a}\right)$,

where $h^{T}$ presents the transpose of the GOSAT pressureweighting function; $X_{a}$ is the GOSAT's prior profile; $\mathbf{A}$ is the averaging kernel matrix of GOSAT; and $X_{h}$ is the modeled vertical $\mathrm{CO}_{2}$ concentration profile interpolated at the GOSAT's vertical layers.

Figure 1 shows the comparison between CTDAS and GOSAT $\mathrm{XCO}_{2}$ for each season during the period of April 2009-December 2010. The spatial distributions of CTDAS and GOSAT $\mathrm{XCO}_{2}$ change seasonally, all with the highest $\mathrm{CO}_{2}$ concentration in spring and the lowest $\mathrm{CO}_{2}$ in summer. These global seasonal variations are reasonable and agree with many previously published results [19, 48]. For the whole study period, there is general agreement between CTDAS and GOSAT with point-by-point correlation of 0.77 $(P<0.05)$. The mean point-by-point difference (CTDAS - GOSAT) is $-0.11 \pm 1.81 \mathrm{ppm}$, seasonally varying from -0.01 to $-0.66 \mathrm{ppm}$, with the largest difference in winter $(-0.66 \pm 1.72 \mathrm{ppm})$ and the smallest bias in autumn $(-0.01 \pm 1.71 \mathrm{ppm})$. This model-observation bias is consistent with the previous results reported by Peters et al. [33] that the CTDAS model can accurately simulate $\mathrm{CO}_{2}$ concentrations, in which CTDAS is on average within $0.5 \pm 0.9 \mathrm{ppm}$ bias compared with the independent column-averaged $\mathrm{CO}_{2}$ concentrations measured by Fourier transform spectrometer (FTS) at the site levels.

We find that the mean standard deviation of GOSAT $\mathrm{XCO}_{2}$ is relatively large $(\sim 1.99 \mathrm{ppm}$ in CTDAS vs. $\sim 2.82 \mathrm{ppm}$ in GOSAT), suggesting a large variation in the satellite-based $\mathrm{XCO}_{2}$, while the modeled column mix fraction retrievals show comparatively unscattered distributions. This is partly due to the effects of heterogeneous sources and complicated climate conditions in the atmosphere, leading to substantial variance of the spatial patterns of atmospheric $\mathrm{CO}_{2}$. This variability is hard to be comprehensively reproduced by modeled $\mathrm{XCO}_{2}$, as only an average estimate is produced (unscattered standard deviation), but well captured by GOSAT with high spread, corresponding to the true atmospheric $\mathrm{CO}_{2}$ variance. On the other hand, perturbation of clouds and aerosols to satellite-based $\mathrm{XCO}_{2}$ could also introduce additional observed scatters into GOSAT measurements and extend the range of standard deviation [20, 30].

Latitudinal comparisons between CTDAS and GOSAT $\mathrm{XCO}_{2}$ retrievals are presented in Fig. 2 with $5^{\circ}$ zonal averages between $40^{\circ} \mathrm{S}$ and $60^{\circ} \mathrm{N}$. Note that the bias and correlation coefficient given here are very different from the values in Fig. 1. The values in Fig. 1 and their associated texts are calculated point-by-point, while the values in Fig. 2 and their associated texts are calculated zone-by-zone by

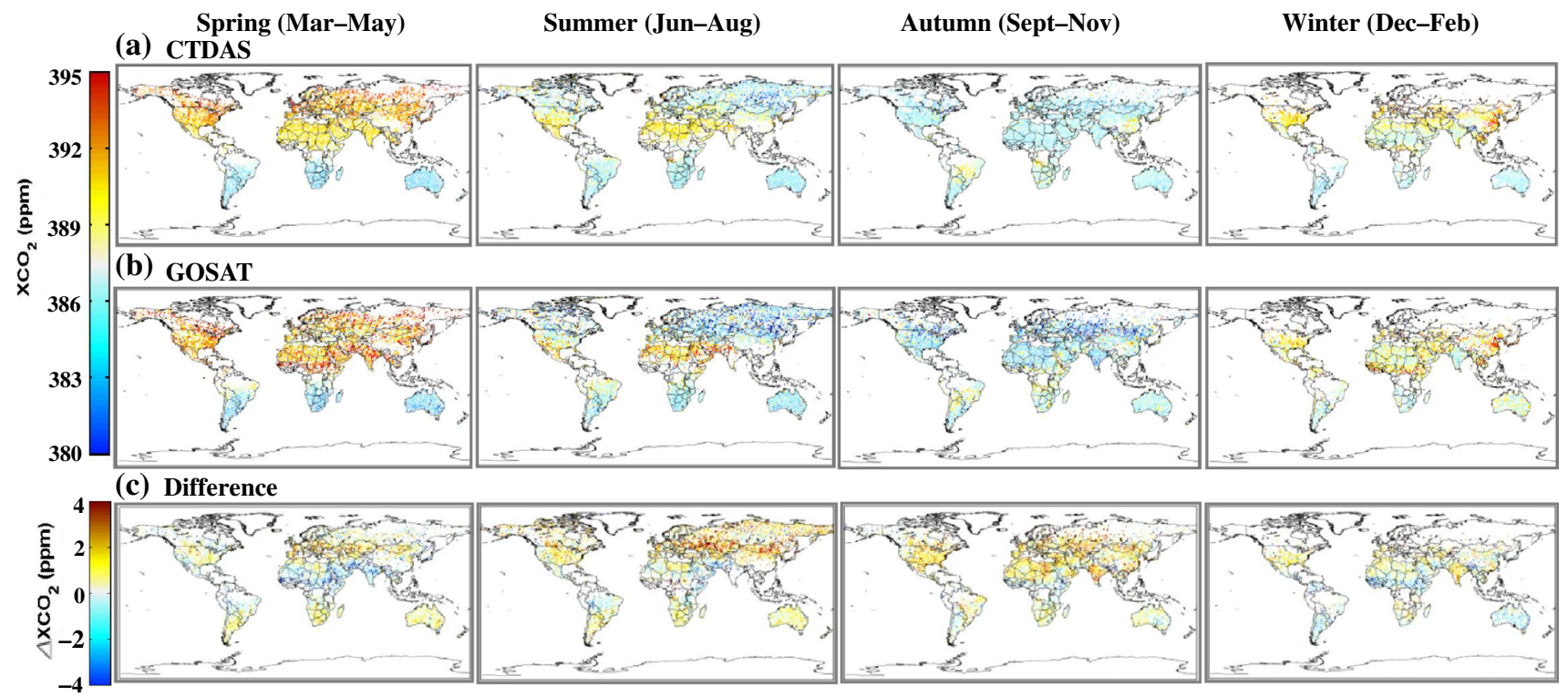

Fig. 1 Comparison of GOSAT $\mathrm{XCO}_{2}$ with CTDAS $\mathrm{XCO}_{2}$ calculated from CTDAS based on GOSAT averaging kernel. Each seasonal columnaveraged $\mathrm{CO}_{2}$ concentrations are shown for (a) CTDAS $\mathrm{XCO}_{2}$, (b) GOSAT $\mathrm{XCO}_{2}$ and (c) the difference between CTDAS and GOSAT $($ difference $=$ CTDAS - GOSAT $)$ 


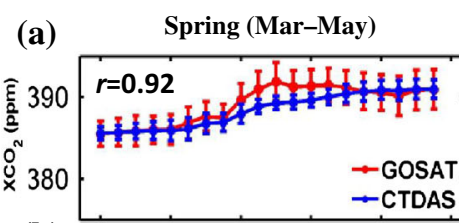

Summer (Jun-Aug)

Autumn (Sept-Nov)

Winter (Dec-Feb)

(b)
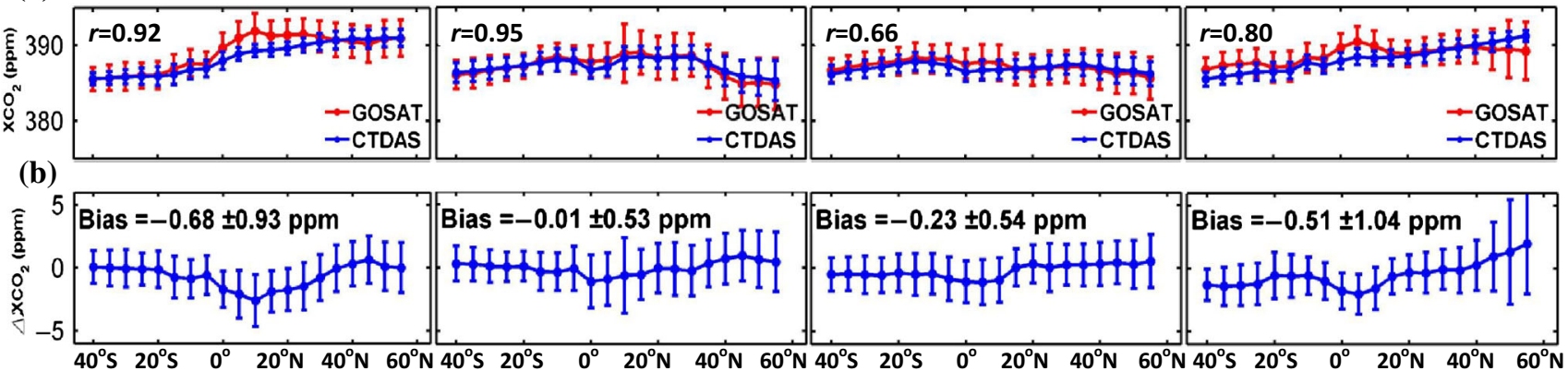

Fig. 2 (a) Latitudinal zonal means and (b) zonal difference as well as their standard deviation between $40^{\circ} \mathrm{S}$ and $60^{\circ} \mathrm{N}$ in $5^{\circ}$ bins for CTDAS and GOSAT $\mathrm{XCO}_{2}$ retrievals are presented during April 2009-December 2010. Note that the bias and correlation coefficient given here are very different from the values in Fig. 1. The values in Fig. 1 and their associated texts are calculated through point-by-point way, while the values in Fig. 2 and their associated texts are calculated through latitudinal zone-by-zone way

latitude. Overall, there is a strong correlation coefficient (latitude zone-by-zone correlation $r=0.79 \quad P<0.05$, Bias $=-0.38 \pm 0.64 \mathrm{ppm})$ between the model and observed zonal latitudinal gradients with a clear seasonal fluctuation. In spring, the latitudinal gradients show higher correlation (latitude zone-by-zone correlation $r=0.92$ $P<0.05$, Bias $=-0.68 \pm 0.93 \mathrm{ppm})$ and lower $\mathrm{XCO}_{2}$ in Southern Hemisphere ( $\mathrm{SH}$ ) than the northern latitudes, which is consistent with the effect of the seasonal cycle on inter-hemisphere $\mathrm{CO}_{2}$ concentration [34]. The zonal mean hemispheric gradients in summer also have high correlation (latitude zone-by-zone correlation $r=0.95 \quad P<0.05$, Bias $=-0.01 \pm 0.53 \mathrm{ppm}$ ) between CTDAS and GOSAT $\mathrm{XCO}_{2}$ retrievals and show a pronounced $\mathrm{CO}_{2}$ decrease in the northern latitudes. In autumn, CTDAS zonal gradient has a relatively poor correlation (latitude zone-by-zone correlation $r=0.66 P<0.05$, Bias $=-0.23 \pm 0.54 \mathrm{ppm}$ ) with observed values. This is inconsistent with the previous findings that comparisons between modeled and observational $\mathrm{CO}_{2}$ seasonal variations show accurate timing in autumn, but a large mismatch summer at the surface sitelevel [49-51]. This discrepancy is likely due to a shift in the timing of summer $\mathrm{XCO}_{2}$, as the $\mathrm{CO}_{2}$ column-averaged dry air mole fraction of CTDAS and GOSAT lagged in the lowest annual cycle causing the stronger summer vegetation photosynthesis uptake of $\mathrm{CO}_{2}$ to occur in July-October, rather than June-August. This resulted in a partial mismatch of the vegetation carbon uptake in the autumn season. For winter, despite poor GOSAT data coverage in the high northern latitude due to persistent cloud and solar zenith angle restriction [34], the $\mathrm{XCO}_{2}$ shows a relatively high latitudinal zone-by-zone correlation $(r=0.80 P<0.05$, Bias $=-0.51 \pm 1.04 \mathrm{ppm})$ but much lower global pointby-point correlation $(r=0.59 P<0.05$, Bias $=-0.66 \pm$ $1.72 \mathrm{ppm}$ ) between GOSAT and CTDAS.

Over the regions of latitude bands of $0^{\circ}-15^{\circ} \mathrm{N}$, we found differences between the CTDAS $\mathrm{XCO}_{2}$ and GOSAT $\mathrm{XCO}_{2}$ of up to $\sim 4$ ppm during April 2009 to December 2010, indicating that large uncertainty potentially exists in the assimilated $\mathrm{CO}_{2}$ for the low-latitude region of the NH. This uncertainty in our estimation can be partly explained by the lack of the available observation sites in the tropical and subtropical areas of the NH. A greater amount of human activities and local carbon emissions over this region also contribute to this uncertainty, further increasing the bias between the simulated and observed values [5, 52-54]. In addition, a large standard deviation $(\sim 2.0 \mathrm{ppm})$ to the simulated-minus-observed difference was found in the Northern middle- to high latitude zones $\left(50^{\circ}-60^{\circ} \mathrm{N}\right)$, mainly due to solar zenith angle restrictions and cloud contamination, which cause large errors in GOSAT $\mathrm{XCO}_{2}$ [20, 34].

Figure 3 shows the time series of $\mathrm{XCO}_{2}$ from CTDAS and GOSAT, for $\mathrm{NH}$ and $\mathrm{SH}$ in $(\mathrm{a}-\mathrm{b})$ as well as seven different continents in $(c-i)$. As the effect of the natural $\mathrm{CO}_{2}$ sources and human activities are more variable on the land, the hemispheric variations of both the CTDAS and GOSAT $\mathrm{XCO}_{2}$ are significantly different, with higher (lower) $\mathrm{XCO}_{2}$ concentrations and more (less) seasonal fluctuation over the $\mathrm{NH}(\mathrm{SH})$ land $[20,48]$. We found that the seasonal cycle agrees well between CTDAS and GOSAT for the NH (point-by-point correlation $r=0.79$ $P<0.05$ ) and the SH (point-by-point correlation $r=0.65$ $P<0.05)$, with bias of $-0.04 \pm 1.96$ and $-0.25 \pm$ $1.45 \mathrm{ppm}$, respectively. This is inconsistent with Cogan et al. [20] and Qu et al. [48] that show a larger bias in the NH. This discrepancy is partly due to the compensation effect of a positive bias (overestimate) in the lowest peak and a negative bias (underestimate) in the highest peak of CTDAS $\mathrm{XCO}_{2}$ time series, leading to a small mean bias in the $\mathrm{NH}$, but still with a large amount of scatter (e.g., standard deviation of $\sim 1.96 \mathrm{ppm}$ ) in simulated $\mathrm{XCO}_{2}$.

The time series of $\mathrm{XCO}_{2}$ shows variations in different months and continents (Fig. 3). In Europe and North 

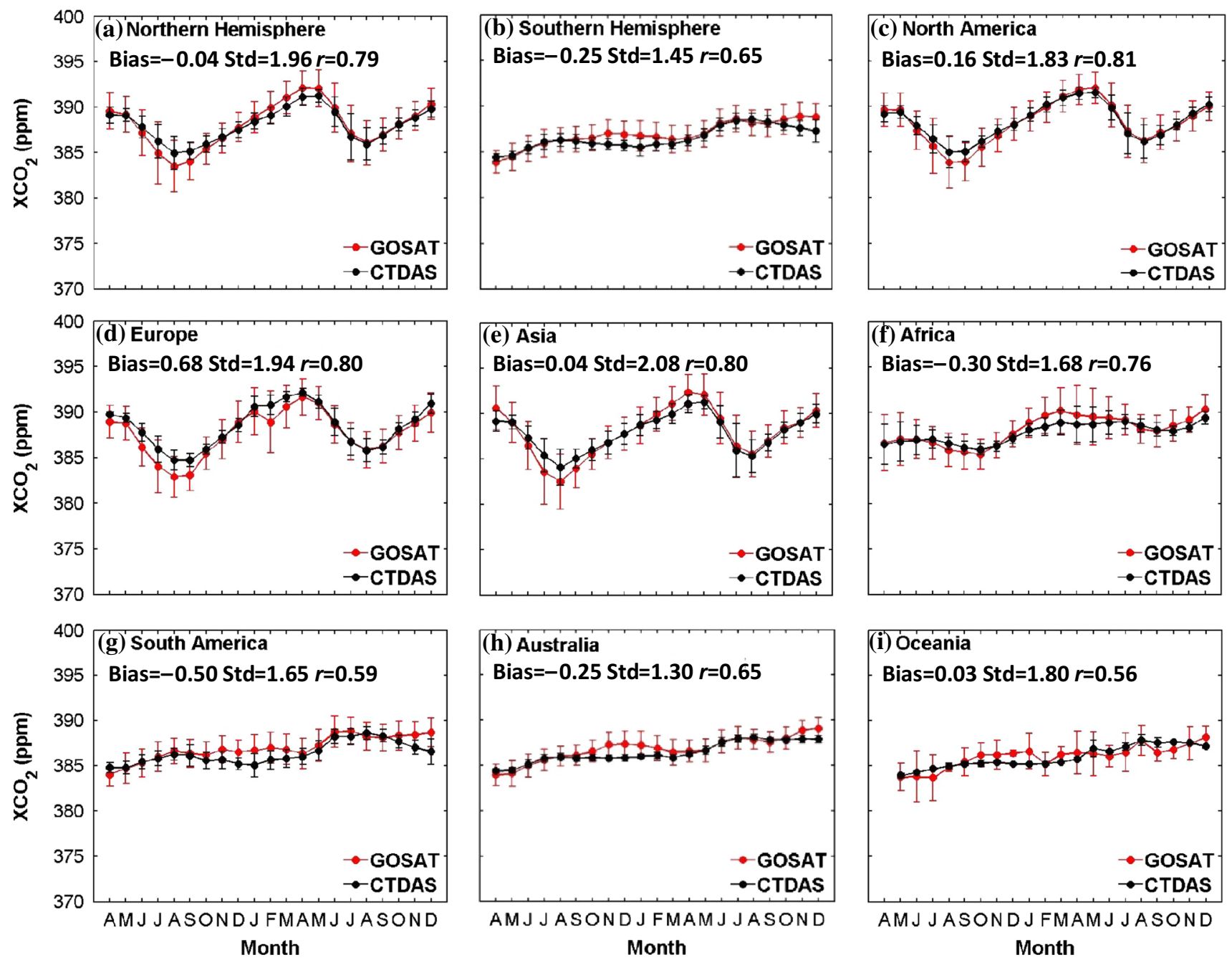

Fig. 3 Comparisons of CTDAS and GOSAT $\mathrm{XCO}_{2}$ for Northern/Southern Hemisphere in (a-b) and for seven continents in (c-i) outlined on the map between April 2009 and December 2010. The error bars represent the standard deviation of the CTDAS and GOSAT data, respectively. Note that the bias and correlation coefficient given here are calculated through point-by-point way

America, CTDAS and GOSAT $\mathrm{XCO}_{2}$ show strong agreement (point-by-point correlation $r=0.80, \quad P<0.05$, $r=0.81, P<0.05$, respectively) in the magnitude and phase of $\mathrm{XCO}_{2}$ with many $\mathrm{CO}_{2}$ sources in this region [19]. Asia, which contains a large area of desert (GOSAT $\mathrm{XCO}_{2}$ observed with high gain model) and high $\mathrm{CO}_{2}$ emissions, has good consistency with the mean $\mathrm{XCO}_{2}$ bias of $0.04 \mathrm{ppm}$ and point-by-point correlation coefficient of 0.80 in time series, but a slightly high standard deviation ( $\sim 2.08 \mathrm{ppm}$ ). In Africa, we found consistency between observed and modeled $\mathrm{XCO}_{2}$ in the amplitude of the seasonal cycle (point-by-point correlation $r=0.76$, $P<0.05)$. In the Northern Hemispheric continents, the model can capture over $80 \%$ of the observed variability, whereas only $50 \%-60 \%$ of the observed variability can be captured in South America and Australia, which may attribute to weakness in the model. As expected, we see a low positive correlation in Oceania between GOSAT and CTDAS (point-by-point correlation $r=0.56, P<0.05$ ), with the magnitude of $\mathrm{XCO}_{2}$ seasonal cycle slightly overestimating the $\mathrm{XCO}_{2}$ in model.

\subsection{Robustness of CTDAS}

CTDAS provides a useful way to estimate $\mathrm{CO}_{2}$ concentrations and fluxes by integrating the atmospheric transport model, the data assimilation technique, prior fluxes and $\mathrm{CO}_{2}$ observations. While incorporating these techniques and data can be powerful to improve the understanding of the $\mathrm{CO}_{2}$ sources and sinks, it also implies that the assimilated $\mathrm{CO}_{2}$ distribution can be influenced by introduced sources of uncertainty in the $\mathrm{CO}_{2}$ assimilation system. Such uncertainty includes uncertainty in the prior fluxes, biases in the observations and errors in the atmospheric 
transport model. Our estimates of $\mathrm{CO}_{2}$ are sensitive to these uncertainties, especially for the systematic errors in the atmospheric transport model [6, 17]. Any mis-specification in the atmospheric transport model, such as insufficient spatiotemporal resolutions, incorrect atmospheric vertical transport and poor driving meteorological data, could introduce large uncertainty in estimates. Another disadvantage to the assimilated $\mathrm{CO}_{2}$ distribution is that the uncertainty associated with the atmospheric transport model is not quantified, which is an important limitation and has been identified as a shortcoming in the current $\mathrm{CO}_{2}$ assimilation system [17, 34, 55]. All of these uncertainties in CTDAS could result in a fraction of the differences between CTDAS and GOSAT.

\section{Conclusion}

We compared simulated $\mathrm{XCO}_{2}$ with the satellite-based measurements to quantify the differences between CTDAS and GOSAT. The spatial and temporal patterns of CTDAS show a high agreement (point-by-point correlation $r=$ $0.77, P<0.05)$ with GOSAT. The mean point-by-point difference (CTDAS - GOSAT) is $-0.11 \pm 1.81 \mathrm{ppm}$, seasonally varying from -0.01 to $-0.66 \mathrm{ppm}$, with the largest difference in winter $(-0.66 \pm 1.72) \mathrm{ppm}$ and the smallest bias in autumn $(-0.01 \pm 1.71) \mathrm{ppm}$. The largest latitudinal zonal bias was found in the band of $0^{\circ}-15^{\circ} \mathrm{N}$ ( $\sim 4 \mathrm{ppm}$ ), partly due to impact of sparse observations and strong influence of human activities and local carbon emissions over this region. We additionally found that the hemispherical and continental differences between CTDAS and GOSAT are typically less than $1 \mathrm{ppm}$, reproducing most of the observed variability for Northern and Southern Hemispheres. However, differences occur in the amplitude of seasonal cycle over different hemispheres, with high consistency in the NH (point-by-point correlation $r=0.79$, $P<0.05$ ) and a weak correlation in the $\mathrm{SH}$ (point-by-point correlation $r=0.65, P<0.05$ ). Overall, the difference of CTDAS and GOSAT is generally small and this comparison will further instruct the inverse modeling of $\mathrm{CO}_{2}$ fluxes using GOSAT.

Acknowledgments We thank Prof. Wouter Peters and Dr. I. T. van der Laan-Luijkx of Wageningen University for providing CTDAS model and technical support and all those for contributing their work to CTDAS. We kindly thank JAXA, NIES and MOE for the GOSAT data and their continuous support as part of the Joint Research Agreement. We also thank the NASA and the ACOS/OCO-2 project for providing ACOS3.3. These data were produced by the ACOS/ OCO-2 project at the Jet Propulsion Laboratory, California Institute of Technology, and obtained from the ACOS/OCO-2 data archive maintained at the NASA Goddard Earth Science Data and Information Services Center. We thank all atmospheric data providers for the NOAA Cooperative Air Sampling network. This work was supported by the Strategic Priority Research Program of the Chinese Academy of Sciences (XDA05040403), the National High Technology Research and Development Program of China (2013AA122002).

Conflict of interest The authors declare that they have no conflict of interest.

\section{References}

1. Machida T, Matsueda H, Sawa Y et al (2008) Worldwide measurements of atmospheric $\mathrm{CO}_{2}$ and other trace gas species using commercial airlines. J Atmos Ocean Technol 25:1744-1754

2. Deng F, Chen JM (2011) Recent global $\mathrm{CO}_{2}$ flux inferred from atmospheric $\mathrm{CO}_{2}$ observations and its regional analyses. Biogeosciences 8:3263-3281

3. Saeki T, Maksyutov S, Saito M et al (2013) Inverse modeling of $\mathrm{CO}_{2}$ fluxes using GOSAT data and multi-year ground-based observations. SOLA 9:45-504

4. Peylin P, Law R, Gurney K et al (2013) Global atmospheric carbon budget: results from an ensemble of atmospheric $\mathrm{CO}_{2}$ inversions. Biogeosciences 10:5301-5360

5. Patra P, Canadell J, Houghton R et al (2013) The carbon budget of South Asia. Biogeosciences 10:513-527

6. Peters W, Krol M, Van der Werf G et al (2010) Seven years of recent European net terrestrial carbon dioxide exchange constrained by atmospheric observations. Glob Change Biol 16:1317-1337

7. Zhang HF, Chen BZ, van der Laan-Luijkx IT et al (2014) Net terrestrial $\mathrm{CO}_{2}$ exchange over China during 2001-2010 estimated with an ensemble data assimilation system for atmospheric $\mathrm{CO}_{2}$. J Geophys Res 119:3500-35158

8. Cao M-K, Tao B, Li K-R et al (2003) Interannual variation in terrestrial ecosystem carbon fluxes in China from 1981 to 1998. Acta Bot Sin 45:552-560 (in Chinese)

9. Cao M, Prince SD, Li K et al (2003) Response of terrestrial carbon uptake to climate interannual variability in China. Glob Change Biol 9:536-546

10. Tian H, Melillo J, Lu C et al (2011) China's terrestrial carbon balance: Contributions from multiple global change factors. Glob Biogeochem Cycle. doi:10.1029/2010GB003838

11. Yu GR, Zhu XJ, Fu YL et al (2013) Spatial patterns and climate drivers of carbon fluxes in terrestrial ecosystems of China. Glob Change Biol 19:798-810

12. Lun F, Li W, Liu Y (2012) Complete forest carbon cycle and budget in China, 1999-2008. For Ecol Manag 264:81-89

13. Liu S, Zhou T, Wei L et al (2012) The spatial distribution of forest carbon sinks and sources in China. Chin Sci Bull 57:1699-1707

14. Fan ZM, Li J, Yue TX (2012) Changes of climate-vegetation ecosystem in Loess Plateau of China. Proc Environ Sci 13:715-720

15. Fang J, Guo Z, Piao S et al (2007) Terrestrial vegetation carbon sinks in China, 1981-2000. Sci China Ser D Earth Sci 50:1341-1350

16. Inoue $\mathrm{M}$, Morino I, Uchino $\mathrm{O}$ et al (2013) Validation of $\mathrm{XCO}_{2}$ derived from SWIR spectra of GOSAT TANSO-FTS with aircraft measurement data. Atmos Chem Phys Discuss 13:3203-3246

17. Basu S, Guerlet S, Butz A et al (2013) Global $\mathrm{CO}_{2}$ fluxes estimated from GOSAT retrievals of total column $\mathrm{CO}_{2}$. Atmos Chem Phys 13:8695-8717

18. Gurney KR, Law RM, Denning AS et al (2002) Towards robust regional estimates of $\mathrm{CO}_{2}$ sources and sinks using atmospheric transport models. Nature 415:626-630 
19. Parker R, Boesch H, Cogan A et al (2011) Methane observations from the Greenhouse Gases Observing SATellite: Comparison to ground-based TCCON data and model calculations. Geophys Res Lett 38:L15807

20. Cogan A, Boesch H, Parker R et al (2012) Atmospheric carbon dioxide retrieved from the Greenhouse gases Observing SATellite (GOSAT): comparison with ground-based TCCON observations and GEOS-Chem model calculations. J Geophys Res. doi:10.1029/2012JD018087

21. Liu Y, Yang D, Cai Z (2013) A retrieval algorithm for TanSat $\mathrm{XCO}_{2}$ observation: Retrieval experiments using GOSAT data. Chin Sci Bull 58:1520-1523

22. Zeng Z, Lei L, Guo L et al (2013) Incorporating temporal variability to improve geostatistical analysis of satellite-observed $\mathrm{CO}_{2}$ in China. Chin Sci Bull 58:1948-1954

23. Kuze A, Suto H, Nakajima M et al (2009) Thermal and near infrared sensor for carbon observation Fourier-transform spectrometer on the Greenhouse Gases Observing Satellite for greenhouse gases monitoring. Appl Opt 48:6716-6733

24. Aumann HH, Chahine MT, Gautier C et al (2003) AIRS/AMSU/ HSB on the Aqua mission: design, science objectives, data products, and processing systems. Geosci Remote Sens IEEE Trans 41:253-264

25. Bergamaschi $P$, Frankenberg C, Meirink JF et al (2009) Inverse modeling of global and regional $\mathrm{CH}_{4}$ emissions using SCIAMACHY satellite retrievals. J Geophys Res 114:D22301

26. Crevoisier C, Chédin A, Matsueda H et al (2009) First year of upper tropospheric integrated content of $\mathrm{CO}_{2}$ from IASI hyperspectral infrared observations. Atmos Chem Phys 9:4797-4810

27. Crevoisier C, Heilliette S, Chédin A et al (2004) Midtropospheric $\mathrm{CO}_{2}$ concentration retrieval from AIRS observations in the tropics. Geophys Res Lett. doi:10.1029/2004GL020141

28. Buchwitz M, Burrows JP (2004) Retrieval of $\mathrm{CH}_{4}, \mathrm{CO}$, and $\mathrm{CO}_{2}$ total column amounts from SCIAMACHY near-infrared nadir spectra: Retrieval algorithm and first results. Proc SPIE. doi:10. $1117 / 12.514219$

29. Yokota T, Yoshida Y, Eguchi N et al (2009) Global concentrations of $\mathrm{CO}_{2}$ and $\mathrm{CH}_{4}$ retrieved from GOSAT: first preliminary results. SOLA 5:160-163

30. O'Dell CW, Connor B, Bösch $\mathrm{H}$ et al (2012) The ACOS $\mathrm{CO}_{2}$ retrieval algorithm-Part 1: description and validation against synthetic observations. Atmos Meas Tech 5:99-121

31. Crisp D, Fisher B, O'Dell C et al (2012) The ACOS $\mathrm{CO}_{2}$ retrieval algorithm-Part II: global $\mathrm{XCO}_{2}$ data characterization. Atmos Meas Tech 5:687-707

32. Wunch D, Wennberg P, Toon G et al (2011) A method for evaluating bias in global measurements of $\mathrm{CO}_{2}$ total columns from space. Atmos Chem Phys 11:12317-12337

33. Peters W, Jacobson AR, Sweeney C et al (2007) An atmospheric perspective on North American carbon dioxide exchange: CarbonTracker. Proc Natl Acad Sci USA 104:18925-18930

34. Hammerling DM, Michalak AM, O'Dell C et al (2012) Global $\mathrm{CO}_{2}$ distributions over land from the Greenhouse Gases Observing Satellite (GOSAT). Geophys Res Lett. doi:10.1029/ 2012GL051203

35. Tadić J, Loewenstein M, Frankenberg C et al (2012) A comparison of in-situ aircraft measurements of carbon dioxide to GOSAT data measured over Railroad Valley playa, Nevada, USA. Atmos Meas Tech Discuss 5:5641-5664

36. Parazoo NC, Bowman K, Frankenberg C et al (2013) Interpreting seasonal changes in the carbon balance of southern Amazonia using measurements of $\mathrm{XCO}_{2}$ and chlorophyll fluorescence from GOSAT. Geophys Res Lett 40:2829-2833

37. Peters W, Miller J, Whitaker J et al (2005) An ensemble data assimilation system to estimate $\mathrm{CO}_{2}$ surface fluxes from atmospheric trace gas observations. J Geophys Res. doi:10.1029/ 2005JD006157

38. Masarie KA, Pétron G, Andrews A et al (2011) Impact of $\mathrm{CO}_{2}$ measurement bias on CarbonTracker surface flux estimates. J Geophys Res 116:D17305

39. Zhang HF, Chen BZ, van der Laan-Luijkx IT et al (2014) Net terrestrial $\mathrm{CO}_{2}$ exchange over China during 2001-2010 estimated with an ensemble data assimilation system for atmospheric $\mathrm{CO}_{2}$. J Geophys Res. doi:10.1002/2013JD021297

40. Zhang H, Chen B, van der Laan-Luijkx I et al (2014) Estimating Asian terrestrial carbon fluxes from CONTRAIL aircraft and surface $\mathrm{CO}_{2}$ observations for the period 2006-2010. Atmos Chem Phys 14:5807-5824

41. Cheng Y, An X, Yun F et al (2013) Simulation of $\mathrm{CO}_{2}$ variations at Chinese background atmospheric monitoring stations between 2000 and 2009: applying a CarbonTracker model. Chin Sci Bull 58:3986-3993

42. Krol M, Houweling S, Bregman B et al (2005) The two-way nested global chemistry-transport zoom model TM5: algorithm and applications. Atmos Chem Phys 5:417-432

43. Rodgers CD, Connor BJ (2003) Intercomparison of remote sounding instruments. J Geophys Res. doi:10.1029/ 2002JD002299

44. Van Der Werf GR, Randerson JT, Giglio L et al (2006) Interannual variability of global biomass burning emissions from 1997 to 2004. Atmos Chem Phys 6:3175-3226

45. Marland G, Boden TA, Andres RJ et al (2003) Global, regional, and national fossil fuel $\mathrm{CO}_{2}$ emissions. Carbon Dioxide Information Analysis Center, Oak Ridge National Laboratory. http:// cdiac.ornl.gov/trends/emis/overview. Accessed 1 May 2007

46. Joint Research Centre/Netherlands Environmental Assessment Agency (2009) Emission Database for Global Atmospheric Research 4.0. http://edgar.jrc.ec.europa.eu. Accessed 21 Jan 2010

47. Jacobson AR, Mikaloff Fletcher SE, Gruber N et al (2007) A joint atmosphere-ocean inversion for surface fluxes of carbon dioxide 1 methods and global-scale fluxes. Glob Biogeochem Cycle. doi:10.1029/2005GB002556

48. Qu Y, Zhang C, Wang D et al (2013) Comparison of atmospheric $\mathrm{CO}_{2}$ observed by GOSAT and two ground stations in China. Int $\mathrm{J}$ Remote Sens 34:3938-3946

49. Peylin P, Law R, Gurney K et al (2013) Global atmospheric carbon budget: results from an ensemble of atmospheric $\mathrm{CO}_{2}$ inversions. Biogeosci Discuss 10:5301-5360

50. Stephens BB, Gurney KR, Tans PP et al (2007) Weak northern and strong tropical land carbon uptake from vertical profiles of atmospheric $\mathrm{CO}_{2}$. Science 316:1732-1735

51. Yang Z, Washenfelder R, Keppel-Aleks G et al (2007) New constraints on Northern Hemisphere growing season net flux. Geophys Res Lett 34:L12807

52. Chevallier F, O'Dell CW (2013) Error statistics of Bayesian $\mathrm{CO}_{2}$ flux inversion schemes as seen from GOSAT. Geophys Res Lett 40:1252-1256

53. Patra P, Niwa Y, Schuck T et al (2011) Carbon balance of South Asia constrained by passenger aircraft $\mathrm{CO}_{2}$ measurements. Atmos Chem Phys 11:4163-4175

54. Belikov DA, Maksyutov S, Sherlock V et al (2013) Simulations of column-averaged $\mathrm{CO}_{2}$ and $\mathrm{CH}_{4}$ using the NIES TM with a hybrid sigma-isentropic $(\sigma-\theta)$ vertical coordinate. Atmos Chem Phys 13:1713-1732

55. Hammerling DM, Michalak AM, Kawa SR (2012) Mapping of $\mathrm{CO}_{2}$ at high spatiotemporal resolution using satellite observations: Global distributions from OCO-2. J Geophys Res. doi:10. 1029/2011JD017015 